\title{
The Aging Lung: Clinical and Imaging Findings and the Fringe of Physiological State
}

\section{Die alternde Lunge: Klinisch-radiologische Aspekte und die Grenzen von Physiologischem und Pathologischem}

Authors

Affiliations
T. H. Schröder ${ }^{3}$, B. Storbeck' ${ }^{1}$ K. F. Rabe ${ }^{2}$, C. Weber ${ }^{3,4}$

Affiliation addresses are listed at the end of the article.
Key words

- ageing lung

- thoracic imaging

- elderly

geriatric medicine

received 26.7.2014

accepted $\quad 7.1 .2015$

\section{Bibliography}

DOI http://dx.doi.org/

10.1055/s-0034-1399227

Published online: 28.4 .2015

Fortschr Röntgenstr 2015; 187 :

430-439 ๑ Georg Thieme

Verlag KG Stuttgart · New York . ISSN 1438-9029

\section{Correspondence}

Dr. Thies Hendrik Schröder

Amalie Sieveking-Hospital,

Academic Teaching Hospital of

the University of Hamburg,

Diagnostic and Interventional

Radiology,

Haselkamp 36

22359 Hamburg

Germany

Tel.: ++ 49/40/64411273

Fax: ++49/40/64411267

thieshs@gmx.net

\section{Abstract}

Since aspects of demographic transition have become an essential part of socioeconomic, medical and health-care research in the last decades, it is vital for the radiologist to discriminate between normal ageing related effects and abnormal imaging findings in the elderly. This article reviews functional and structural aspects of the ageing lung and focuses on typical ageing related radiological patterns.

Key points:

- The physiological aging process of the thoracic organs shows typical structural and functional aspects.

- Mild interstitial fibrosis and focal parenchymal abnormalities like septal thickening can be diagnosed frequently - whereas a clinical correlate is often lacking.

- With increasing patient age, the influence by various intrinsic and extrinsic factors (including comorbidities of the patient, and drug inhalation toxicants) also increases.

- A growing spectrum of imaging techniques (including functional cardiopulmonary MRI, MRI spectroscopy, hybrid-techniques) is confronted by rare empiric data in the very old people (aging 80 years and older).

Citation Format:

- Schröder TH, Storbeck B, Rabe KF. et al. The Aging Lung: Clinical and Imaging Findings and the Fringe of Physiological State. Fortschr Röntgenstr 2015; 187: 430-439

\section{Zusammenfassung}

$\nabla$

Der demografische Wandel ist in den letzten Jahrzehnten zunehmend in den Fokus sozioökonomischer, medizinischer und versorgungsrelevanter Forschungen getreten. Dabei steht der klinische Radiologe durch vermehrten Einsatz von
Schnittbildverfahren auch in der Thoraxradiologie einer Grauzone zwischen „Zufallsbefunden“ und „Frühformen klinisch-relevanter Lungenerkrankungen“ gegenüber.Das Wissen um die Grenzen zwischen physiologischen, alterungsbedingten Veränderungen des Thorax im Alter auf der einen und bereits klinisch-relevanten pathologischen Veränderungen auf der anderen Seite, ist Fokus dieses Artikels.

\section{Introduction}

$\nabla$

In 2050 more than $40 \%$ of the population of Germany will be over 60 years of age, whereas in particular those over 80 years of age will increase disproportionately and could reach approx. $15 \%$ [1]. The anticipated life expectancy of today's 60 -year-old is about 85 years; today's 80 -year-old can expect to live to age 89 [2]. There are some pitfalls when distinguishing physiological and pathological changes of the lung among older persons; such drawbacks are the subject of this article. Since there is no uniform definition of age [3], persons older than 60 years of age will be arbitrarily defined here as the cohort of the "elderly". Actually this lower threshold - which can vary individually - could be set at 70 or 80 years.

The following issues should be addressed:

- Which structural and functional changes do the thoracic organs exhibit in old age?

- Which typical and common radiological changes occur? What incidental findings are without clinical significance and which findings may have clinical implications?

- What influence do extrinsic (medication, polypharmacy, environmental influences) and intrinsic (cardiopulmonary events, other systemic underlying disorders, e.g. 
diabetes) influence factors have on lung changes in old age?

- What value does thoracic imaging have in old age, and what empirical data are missing?

\section{Functional and Structural Changes of the Lungs and Thorax \\ $\nabla$}

The histopathological and pulmonary changes in elderly healthy volunteer subjects have been extensively studied in recent decades $[4,5]$. On the other hand, a healthy elderly norm population used for reference is rare, and the number of volunteer subjects is frequently small. Thus Bisschop et al. [6], in their cohort of 66 to 88-year-olds for a study of pulmonary obstruction and lung function parameters, found that of their initial selection of 750 people, only 116 , i. e. $15.5 \%$ "healthy" volunteers could be identified, that is, asymptomatic non-smokers without pre-existing conditions.

\subsection{Structural aspects}

Thoracic wall and (accessory) respiratory muscles: With increasing age, rigidity of the thoracic wall increases due to calcification of costosternal joints and osteoarthritis of the costovertebral junctions on the one hand, and on the other, increasing kyphosis of the thoracic spine due to vertebral fusion. The latter also exhibits effects upon diaphragm mobility and force $[4,7,8]$, potentially causing restrictive respiratory disorders. The internal intercostal muscles which support active expiration atrophy with increasing age; expectoration consequently becomes difficult, and infectious respiratory disease is fostered. In addition, the amount of effort required by the diaphragm and abdominal muscles to effect breathing increases.

\section{Lung parenchyma:}

Lung elasticity decreases with age. This primarily affects the interconnection of elastic fibers; additionally increased release of the so-called neutrophil elastase with the destruction of elastin has been studied [4]. Ex-vivo studies on human autopsy specimens have demonstrated an increase in the size of the alveolar ducts as well as the alveoli [9]. On the other hand, the pathognomonic destruction of the alveolar walls in emphysema is not an element of the physiological aging process.

\subsection{Pulmonary aspects}

As elasticity of the lung diminishes, its compliance (extensibility) likewise decreases, with reduced compliance of the chest due to rigidity. Total lung capacity does not essentially change with aging. At end expiration however, residual volume increases, leading to a decline in vitality. Reduced supporting tissue surrounding the respiratory bronchioles results in significantly premature collapse or closing of the small air passages $[10,11]$ with air trapping as radiological correlate. A related component of the peripheral air passages is consequently not involved in gas exchange. In addition to decreased capillary density per acinus, the previously-mentioned inhomogeneity in the ventilation/perfusion ratio ensures reduced capacity for the diffusion of carbon monoxide (CO transfer factor $\mathrm{D}_{\mathrm{LCO}}$ ) [11 - 13].

\section{Radiological Aspects}

$\nabla$

Essentially based on radiological symptom patterns, the following discusses their implications and significant related studies.

\subsection{Density reduction of lung parenchyma}

Age-related hyperinflation, "senile emphysema", pulmonary emphysema and COPD in old age

Physiological size increase of alveoli and alveolar ducts as a radiological correlate contrasts with the age-related density reduction of the lungs by approx. $50 \mathrm{HU}$ between the ages of 20 and 70 [14], and can hardly be differentiated visually by the investigator. At the same, the prevalence of COPD increases with age, whereas the extent of air passage obstruction and dysfunction as well as the extent of emphysema can vary according to phenotype. In their meta-analysis, Halbert et al. [15] describe a prevalence of COPD at around $15 \%$ for those 65 years of age and older. Histological studies by Verbeken et al. [10] demonstrated that age-related alveolar hyperinflation is homogeneously distributed across the entire lung, whereas emphysematous pulmonary changes mainly affect the upper or lower lobe, depending on the phenotype. The concept "senile emphysema" describing physiological alveolar hyperinflation without destruction is considered obsolete $[9,16]$. Since the presence of pulmonary emphysema represents an independent risk factor for developing lung cancer [17], and since procedures are increasingly being used to reduce lung volume (e.g. endobronchial valves, coils), when conventional thoracic Xrays are performed, the examiner should look for typical signs of advanced pulmonary emphysema (flattening of the diaphragm, expanded retrosternal and retrocardial airspace, lung hypertransparency, peripherally rarefied vessels). For low and medium grade emphysematous changes, HRCT is clearly superior to conventional X-ray imaging [18]. In addition to visual emphysema grading as described by Bankier et al. [19], quantitative methods particularly demonstrate high correlation with pulmonary parameters [20]. These offer measurement during inspiration (extent of emphysema) as well as expiration (air trapping as correlate of the extent of air passage obstruction). Coronal and sagittal minimum intensity projections (MinIP) are recommended for orientation purposes. Fig. 1 shows bullous pulmonary emphysema with UIP pattern with suspected coincidental idiopathic pulmonary fibrosis.

\subsection{Density increase of lung parenchyma}

A typical finding in thoracic CT, particularly in the aged, is reversible, relatively homogeneous ground glass opacity in the basal dependent regions of the lung ( $\square$ Fig. 2). Shallow inspiration depth and position-dependent (hypostatic) alteration of the parenchyma are common causes. Practical note If there is clinical suspicion of interstitial pulmonary disease (see section 2.5) and the CT reveals density increases in the dependent lung regions, supplementary sequential layer images should be obtained in the prone position in order to determine reversibility of the density increases as an indication of hypostasis. If ground glass changes persist in the prone position, and additional signs of fibrosis such as honeycombing or tractive bronchiectasis are present, then usual interstitial pneumonia (UIP) should be consid- 

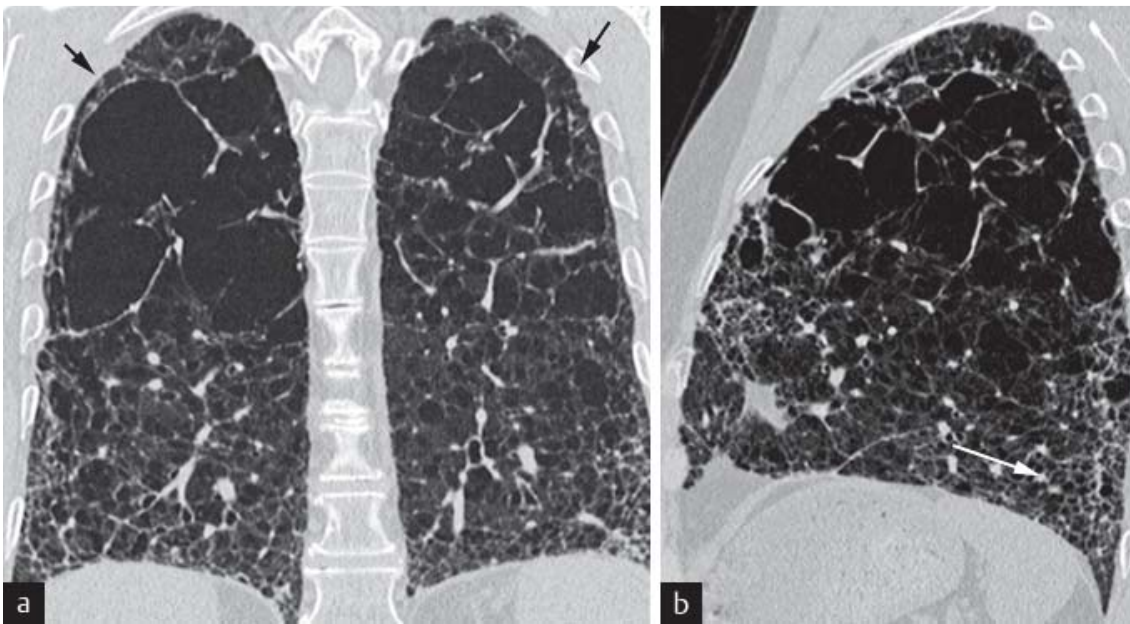

Fig. 1 Emphysema and UIP pattern. HRCT of the lung of a 70-year-old patient with dyspnea in coronal $\mathbf{a}$ and sagittal $\mathbf{b}$ reconstruction. Advanced bullous-confluent centrilobular emphysema (upper lobe predomination, black arrows). Subpleural pulmonary fibrosis with honeycombing (white arrow), septal thickening and traction bronchiectasis, UIP pattern in IPF.

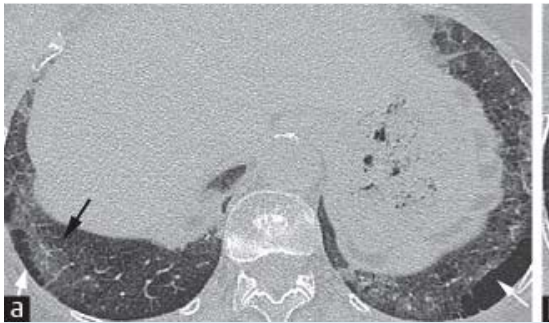

Fig. 2 Paraseptal emphysema and dependent density ground-glass. HRCT of the lung of a 71-year-old patient with clinical suspicion of ILD in collagenvascular disease. In addition to a paraseptal emphysema (white arrow) a diffuse ground-glass and minor interlobular septal thickening (black arrow)

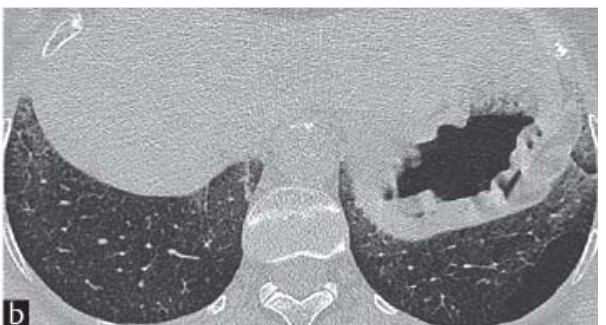

is shown. The diagnosis of a (cellular) NSIP could be favored. In additional spaced axial scans in the prone position (for better comparison already rotated by $180^{\circ}$ ) the alterations are (almost) completely reversible $\mathbf{b}$. ered, e.g. in cases of idiopathic pulmonary fibrosis or associated pulmonary alterations; however, consideration should likewise be given to non-specific interstitial pneumonia (NSIP) such as appears in cases of collagenosis, but also occurring idiopathically. NSIP can also be manifested as diffuse subpleural ground glass without indication of fibrosis. The so-called mosaic pattern, qualitatively recognizable focal pulmonary parenchymal density differences during inspiration is frequently limited to the secondary lobule or air trapping during expiration, with a lack of density increase of lung tissue due to retained air. This is a common finding in aging patients, but may also be an expression of manifest pulmonary disease. Lee et. al [21] showed that in an asymptomatic cohort $\geq 61$ years of age $(\mathrm{N}=17)$, the portion of subjects with air trapping was $76 \%$. Misdiagnosis of a mosaic pattern or even generalized "alveolitis"-related ground glass may be the result of accidental images of expiration or respiration due to limited patient cooperation during the examination, particularly during sequential HR imaging.

\subsection{Incidental pulmonary nodules: solid, partially solid, ground glass}

The increasing number of lung cancer screening studies in the $1990 \mathrm{~s}$ was accompanied by the recognition of the prevalence of incidentally-detected pulmonary nodules (or nodular shadows) among asymptomatic volunteer subjects, mainly smokers or former smokers between the ages of 55 and 75. The proportion of CT scans detecting at least one non-calcified nodule ranges from approx. $25 \%$ [22] to approx. $70 \%$ [23]. In the course of further invasive diagnosis only $1 \%$ of detected nodules were found to be malignant. $80 \%$ of the malignoma were larger than $8 \mathrm{~mm}$. The Fleischner Society established recommendation for the management of pulmonary nodules based on the size and risk stratification of nodules found in volunteer subjects. In addition, algorithms were established for subsolid nodules and ground glass nodules [24, 25]. There is no evidence to support a different procedure among very old subjects (> 75 years). Further, geographic and environmental factors have been insufficiently included in the risk stratification. - Fig. 3 shows a focal ground glass lesion and a solid pulmonary nodule. In the future, low-dose screening CT, using visual and quantitative methods, could be employed to detect the presence of pulmonary emphysema and early forms of interstitial pulmonary disease [26].

\subsection{Changes to the airways}

Matsuoka et al. [27] showed a significant relationship between aging and the ratio of the diameter of the bronchus to the accompanying artery (bronchoarterial ratio). This was explained by relative hypoxemia existing in an aged cohort which caused vasoconstriction and (relative) bronchial dilation, effects which are seen among populations living at high altitude. In Matsuoka's cohort (age: 73.6 \pm 6.2 years, $\mathrm{N}=27$ ), the bronchoarterial ratio among $41 \%$ of subjects was greater than 1 . 


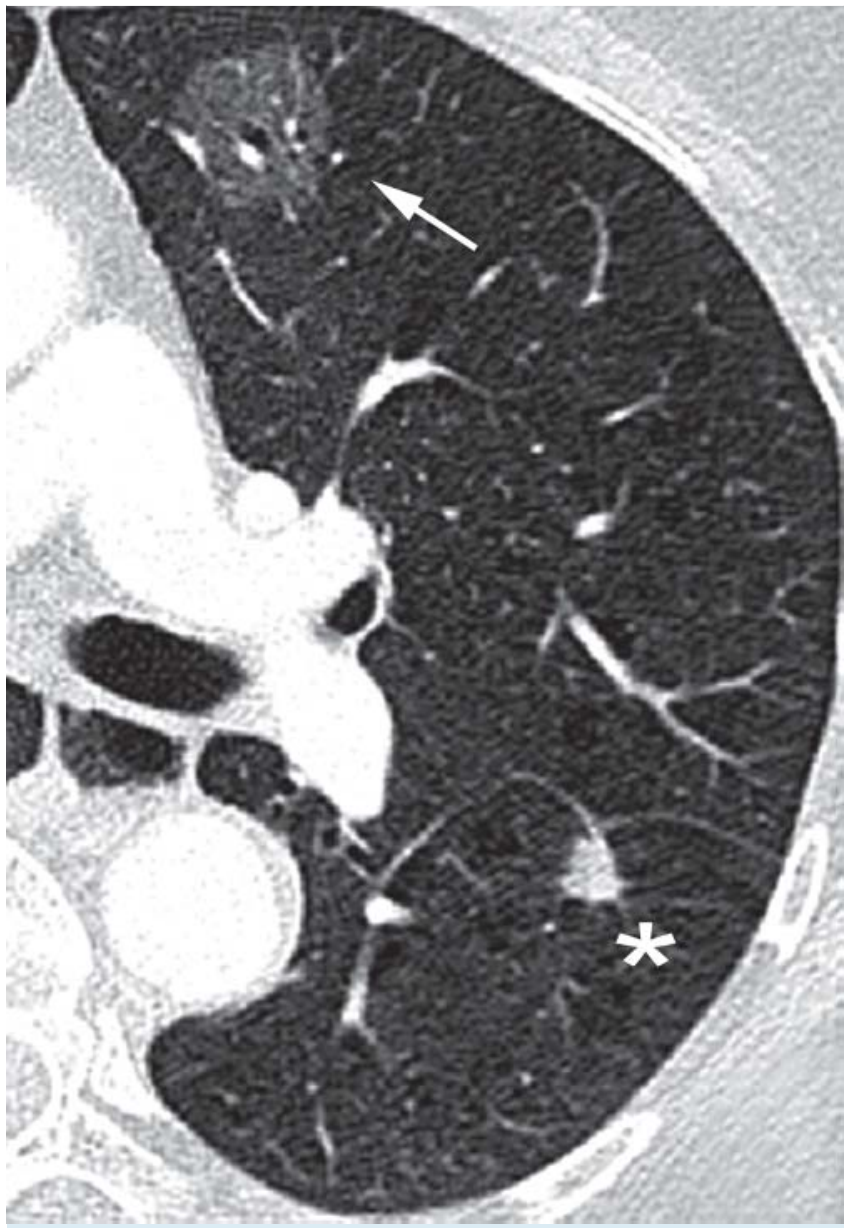

Fig. 3 Two adenocarcinomas of the lung with different growth type. Contrast-enhanced CT of the lung of a 73-year-old patient with suspected malignancy due to a solitary pulmonary nodule detected on a chest $\mathrm{x}$-ray. In addition to the solid nodule adjacent to the fissure in the superior segment of the left lower lobe (white asterisk *), a tumor-suspicious groundglass lesion was detected in the left upper lobe (white arrow). Histology revealed an adenocarcinoma of the lung in each case with lepidic-predominant growth type (ground-glass lesion) respectively acinar and solid predominant growth type (solid nodule).

Practical note Caution should be observed with respect to a hasty diagnosis of bronchiectasis in the elderly. Additional criteria for diagnosis of bronchiectasis should include a bronchoarterial ratio greater than 1.5 , bronchi visible into the direct periphery and lack of distal tapering of the bronchial diameter. In addition, complications of bronchiectasis such as exudative bronchiolitis and mucus retention are further evidence. Systemic diseases such as rheumatoid arthritis or chronic inflammatory bowel disease frequently coincidentally exhibit changes in the airways. The diagnosis report of elderly patients with only discretely expanded bronchial diameter without additional signs of bronchiectasis should document this (e.g. "borderline dilated bronchial system"). The degree of inspiration influences this, on the peripheral airways in particular [28].

The diagnosis of bronchial wall thickening using HRCT can only be passably judged. As a consequence of chronic airway disease, it is difficult to distinguish bronchial wall thickening from peribronchial cuffing, i. e. thickening of the bronchial sleeves, in a conventional radiograph such as of

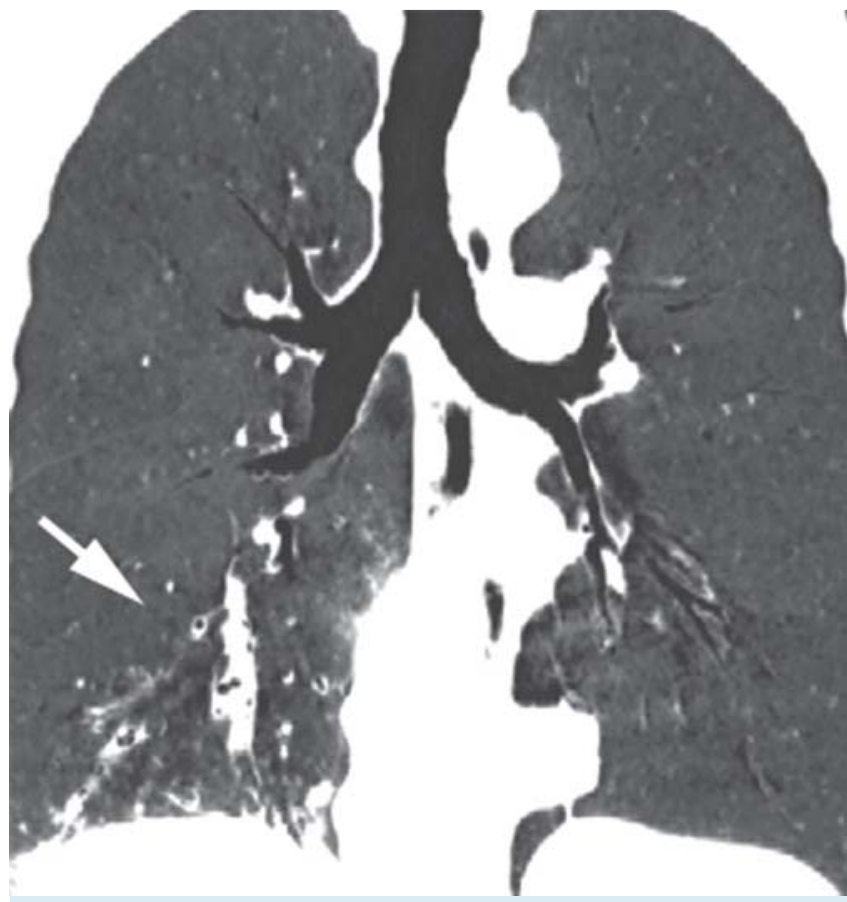

Fig. 4 Bronchiectasis. HRCT of the lungs in coronal MinIP reconstruction for recurrent pulmonary infections of unknown origin. Cylindrical bronchiectasis predominantly in the right lower lobe with mucus plugging (white arrow) and minimal tree-in-bud pattern in exudative bronchiolitis and bronchopneumonia.

blockage of the pulmonary vein due to heart failure. A volume CT with secondary calculated HR slices is preferred to clarify possible bronchiectasis in the elderly. Coronal minimum-intensity projections (MinIPs) used for secondary reformatting disclose more discrete findings ( $\bullet$ Fig. 4).

\subsection{Interstitial lung abnormalities - incidental findings} without disease or subclinical ILD?

Utilization of new substances such as pirfenidone when treating low-to-mid-grade idiopathic pulmonary fibrosis (IPF) increases the importance of early diagnosis of IPF within the "therapeutic window". This places HRCT of the lung in a position of prominence [29] in order to identify patients exhibiting interstitial pulmonary alterations following a possible or established UIP pattern. Algorithms for screening an IPF - a combination of clinical signs (e.g. auscultatory crepitation, persistent cough, dyspnea) and HRCT- are currently the subject of prospective studies $[26,30]$.

In secondary analyses of large-scale lung cancer screening programs, such as the American National Lung Screening Trial (NLST), using an age cohort of 55 to 74-year-olds, it has been shown that interstitial, non-nodular changes occur in about $10 \%$ of cases, whereas non-fibrotic changes appear in approx. $6 \%$ of cases (i.e. ground glass, mosaic pattern, consolidation). Fibrotic changes occur at a rate of $2 \%$ (i.e. ground glass and septum thickening, septum thickening only, honeycombing); mixed fibrotic/non-fibrotic findings occur in approx. $2 \%$ of cases [31, 32]. Typically the screening trials include smokers and former smokers, but not those who have never smoked (i.e. non-smokers). There is no empirical data on very old subjects ( $>80$ years). Only 

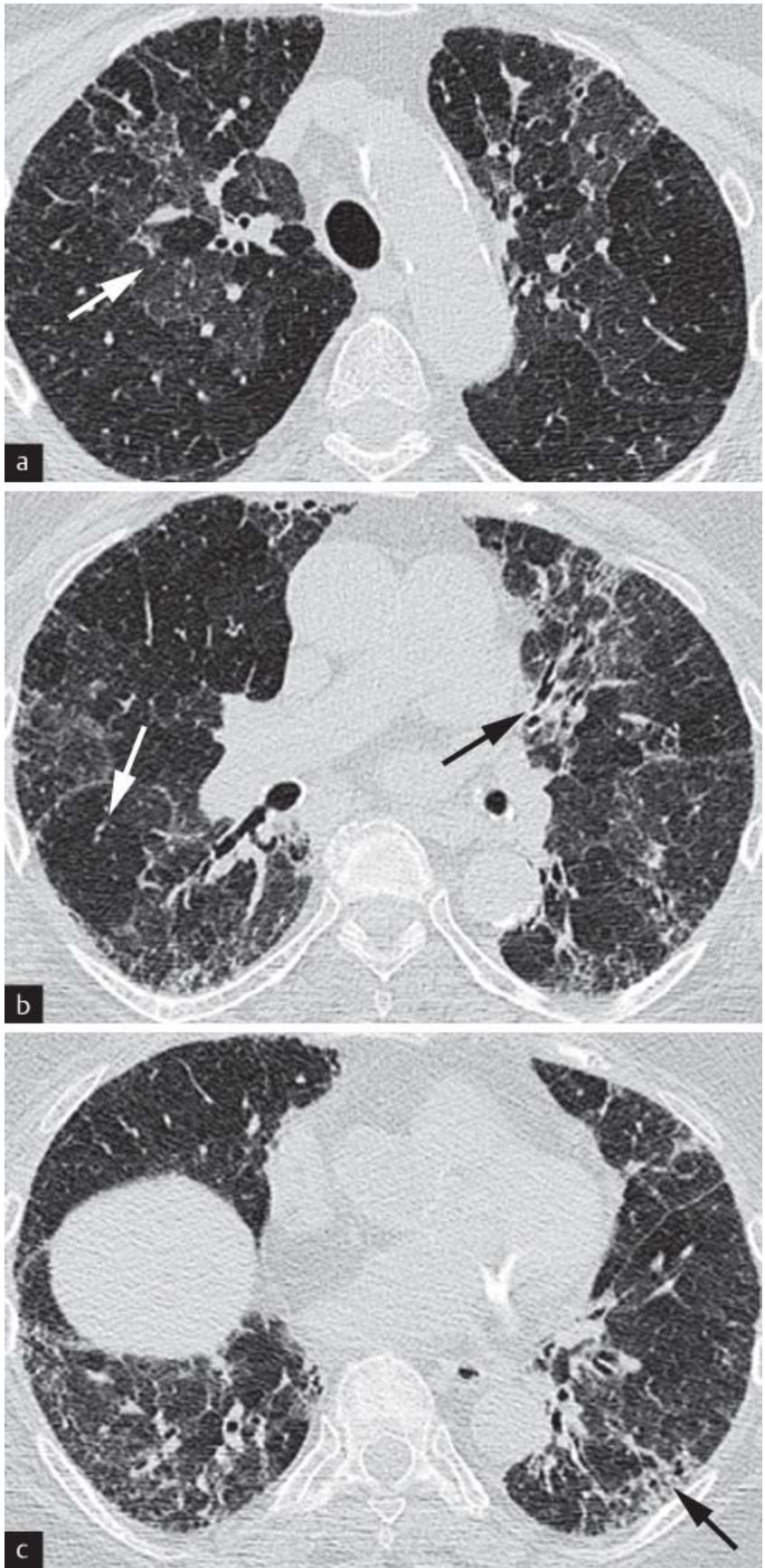

Fig. 5 Uncharacteristic pulmonary fibrosis. HRCT of the lung of a 87-yearold patient. In addition to a distinct mosaic pattern (white arrows), there are findings of uncharacteristic fibrotic lung changes (black arrows) with septal thickening, traction bronchiectasis and (not shown here) scattered honeycombing. The suspected diagnosis of chronic hypersensitivity pneumonitis was not supported by BAL and history. There were comorbidities with chronic left ventricular dysfunction and gastroesophageal reflux. Polypharmacy without higher grade 'suspicious' drugs. The differential diagnosis favored a mixed pattern due to uncharacteristic pulmonary fibrosis and chronic pulmonary venous congestion. Forced invasive clarification was omitted due to age and lung functional limitation.

Copley et. al [33] reported incidental pulmonary HRCT findings in a small cohort (age $80.6 \pm 4.2, \mathrm{~N}=40$ ) of non-smokers. All scans were performed in the prone position: predominantly subpleural and basal reticular thickening (septum thickening) was evident in $60 \%$ of the group of

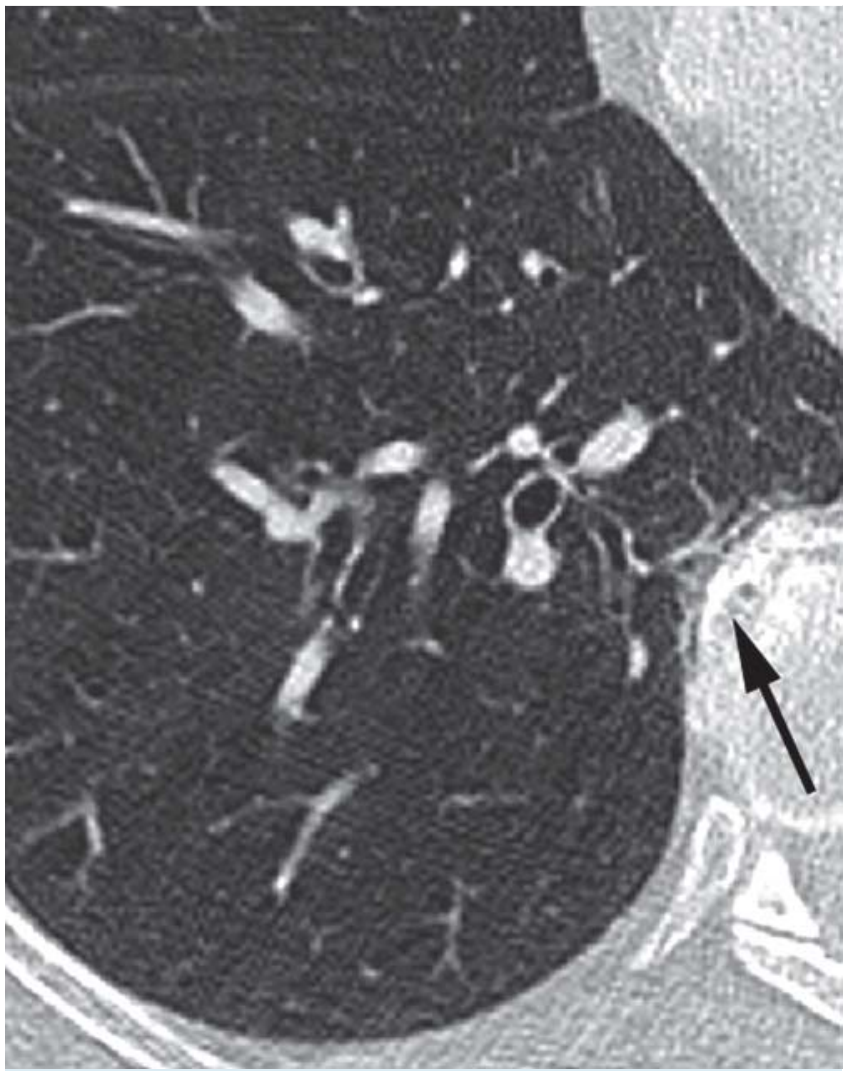

Fig. 6 Fibrosis adjacent to an osteophyte. Detail of a CT of the lung of a 76-year-old patient for tumor staging in lung cancer. As a secondary finding, discrete linear opacification is show adjacent to a prominent osteophyte (black arrow).

above-75-year-olds; isolated pulmonary cystic lesions were detected in $25 \%$ of the age group. The absence of ground glass lesions was striking, possibly due to an optimized protocol in the prone position to exclude effects of hypostasis. A histopathological correlation with the radiological findings could not be made, since no assertion could be made regarding the proportion of early forms of e.g. IPF. The majority of subjects exhibited unremarkable, i.e. ageappropriate, results in the pulmonary function test. The differentiation of the described septum thickening from early forms of IPF and other forms of interstitial lung disease (ILD) is both elementary - and highly challenging [34] (৫ Fig. 5). A frequent finding in the elderly includes focal interstitial thickening adjoining osteophytes of the thoracic spine discovered in approx. $45 \%$ of cases [35] ( $\odot$ Fig. 6).

Frequently pharmaceutically-associated ILD must be considered. Despite numerous studies [36, 37] and a few internet databases (e.g. http://www.pneumotox.com), it is still difficult to make a coincidental or even causal correlation with a specific noxa ( $\bullet$ Fig. 7). The interaction of polypharmacy - defined as regular intake of four or more medications - on the lung and its radiological correlates is still not considered. In practice, particularly with geriatric patients with comorbidities and multiple medications, narrowing down to a sole diagnosis of "medication-induced ILD" is rarely possible. Brief follow-ups using chest images, especially using a few sequential HR layers with acceptable radiation exposure can favor limiting differential diagnosis to 


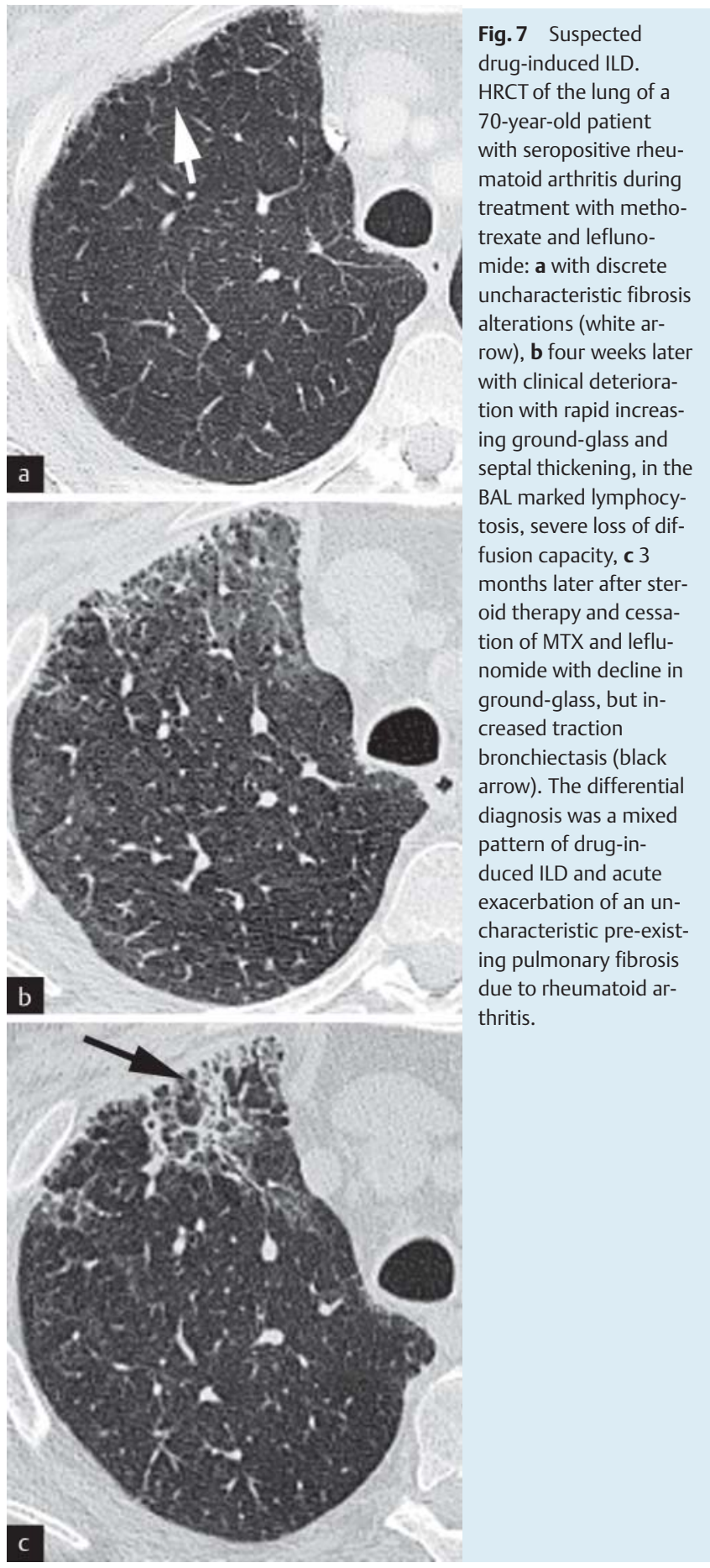

a few possibilities ( $\bullet$ Fig. 7, 8). Camus et al. [37] identify a variety of drugs that frequently induce ILD, including amiodarone, antibiotics (especially nitrofurantoin), nonsteroidal antiphlogistics, chemotherapeutics (bleomycin, cyclophosphamide, gemicitabine, docetaxel, methotrexate). There are no data regarding the prevalence of pulmonary toxicity of medications most frequently prescribed to the elderly and their radiological manifestation.

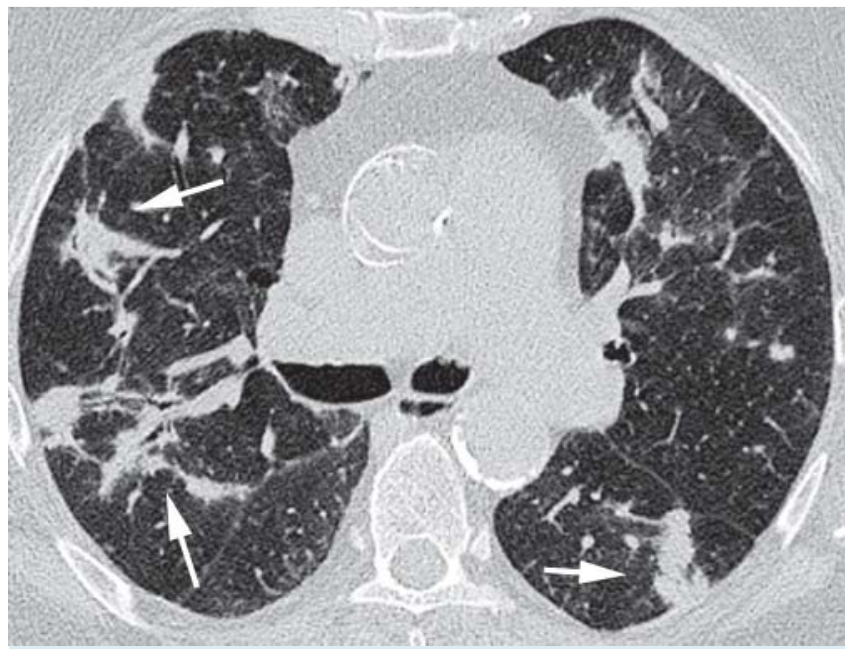

Fig. 8 Amiodarone lung. HRCT of the lung of a 70-year-old patient taking amiodarone for several months. Peribronchial amorphous consolidation, partly with air bronchogram, (white arrows). Diagnosis of an organizing pneumonia in drug-induced ILD (amiodarone) was favored and supported by the BAL with CD-8 dominant lymphocytosis.

\section{Recommendations for Differential Diagnosis of the Thorax in the Elderly -Perspectives on Thoracic Imaging of Elderly Patients and the Limits of Evidence $\nabla$}

This exposition has not identified the numerous "border areas" of imaging of the aging heart and vascular system. Also excluded are the descriptions of manifest disorders beyond the border area: pulmonary infectious diseases in old age, lung cancer and other pulmonary malignancies, pleural lesions, pulmonary thromboembolisms as well as pulmonary hypertension.

- Fig. 9 again summarizes essential alterations to the geriatric thorax and visible in thoracic CT and provides diagnostic support for the gradual escalation of radiological diagnosis of the elderly.

In order to obtain our own results for age-specific pulmonary changes, thoracic CT scans performed consecutively between May and September 2014 in our Radiology Department in a basic and standard care hospital were retrospectively evaluated. Two cohorts (age $\leq 50$ years ["young"] vs, $\geq 80$ years ["old"] with $29 / 30$ volunteer subjects were compared: "young" cohort (average age 40.8 \pm 8.0 ; male:female $41.4 \%: 58.6 \%$ ) vs. "old" cohort (average age $85.8 \pm 3.5$; male:female $43.3 \%: 56.7 \%$ ).

Supporting indications in "young" cohort": exclusion of pulmonary embolism $(16 / 29,55 \%)$, suspicion of pleural empyema $(5 / 29,17 \%)$, tumor staging with suspicion of malignancy $(4 / 29,14 \%)$, spontaneous pneumothorax, expansion and identification of cause $(2 / 29,7 \%)$ and thoracic trauma $(2 / 29,7 \%)$; in the "old" cohort: tumor staging with suspicion of malignancy $(13 / 30,43 \%)$, exclusion of pulmonary embolism (10/30, 33\%), quantification of pneumonia (3/30, $10 \%)$, exclusion of aortic dissection (1/30, $3 \%)$, exclusion of pacemaker sensor dislocation $(1 / 30,3 \%)$, thoracic trauma (1/30, $3 \%)$, and exclusion of pulmonary fibrosis (1/30, $3 \%)$.

- Table 1 shows the frequency of pulmonary findings of our cursory study related to the "young" and "old" cohorts. 


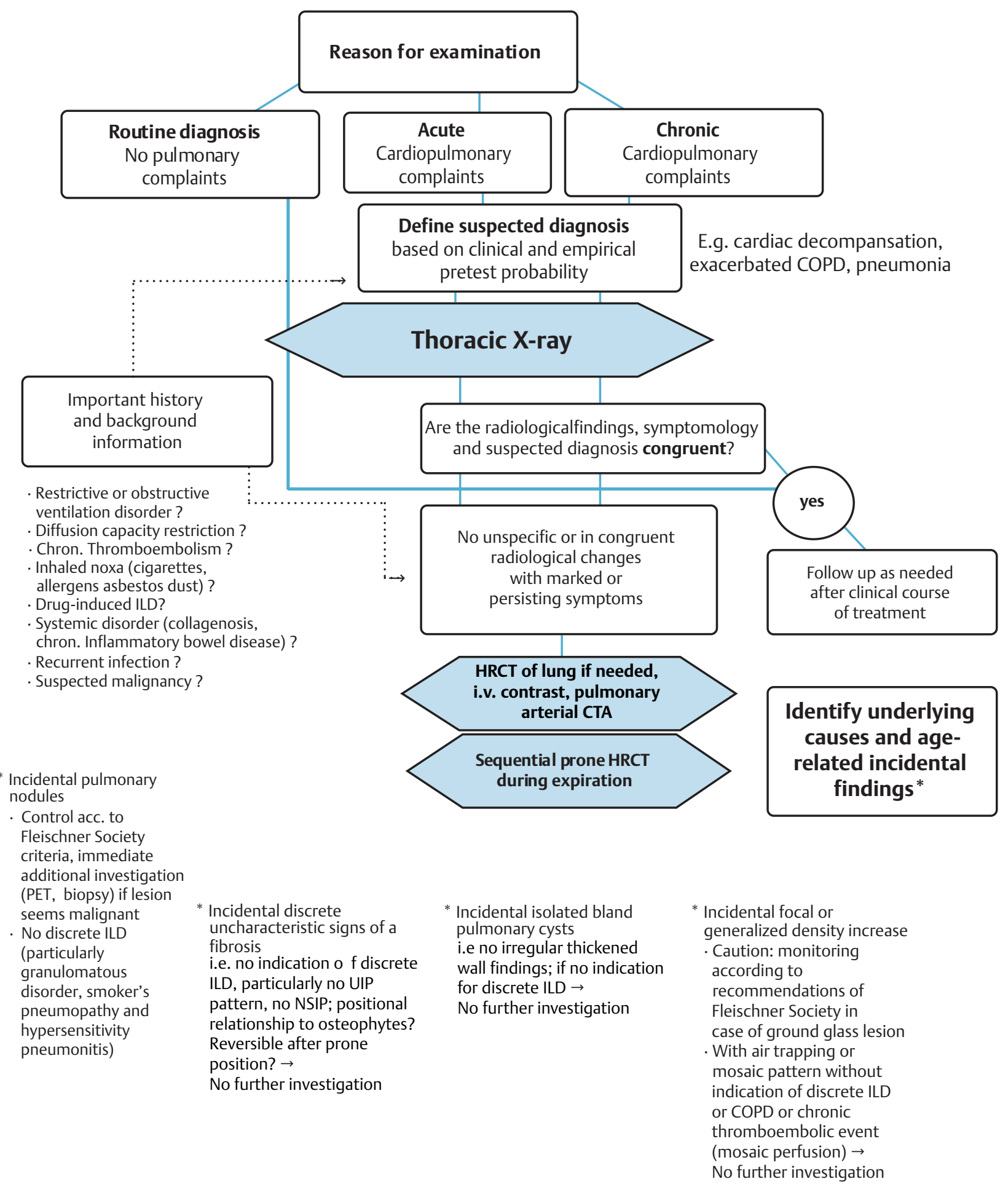

Fig. 9 Differential diagnostic considerations in the diagnostic evaluation of cardiopulmonary diseases in the elderly. Algorithm does not include other modalities, in particular echocardiography, MRI and scintigraphy. If the changes in HRCT lung can not just be explained by age-related incidental findings, the radiologist should try to minimize the number of differential diagnoses with close historical and clinical background information.
Of the 30 examined volunteers $\geq 80$ years of age, there was an $80 \%$ (24/30) adequate radiological correlate for the described symptoms. Four subjects exhibited clear fibrotic and/or emphysematous pulmonary changes which likewise correlated with the symptomology. Except for two uncharacteristic nodules or pleural dome callosity, two subjects exhibited no indicative findings. 
Table 1 Results of our retrospective study of radiological changes in thoracic CT differentiated by collective "young" ( $\leq 50$ years) vs. "old" ( $\geq 80$ years) and the preliminary radiological diagnoses according to categories.

\begin{tabular}{|c|c|c|c|c|}
\hline Radiographic Changes & $\begin{array}{l}\text { "young" co- } \\
\text { hort [n=29] }\end{array}$ & Description & $\begin{array}{l}\text { "old" cohort } \\
{[n=30]}\end{array}$ & Description \\
\hline nodules & $8 / 29[28 \%]$ & $\begin{array}{l}5 / 8 \text { with two nodules up to } 6 \mathrm{~mm} \text { size, } \\
\text { subpleural or interlobular; } \\
2 / 8 \text { with multiple pulmonary nodules in } \\
\text { breast cancer and lung cancer; } \\
1 / 8 \text { with suspected malignancy }\end{array}$ & $13 / 30[43 \%]$ & $\begin{array}{l}\text { 7/13 with suspected malignancy; } \\
5 / 13 \text { with three nodules up to } 6 \mathrm{~mm} \\
\text { size, interlobular, nonspecific; } \\
1 / 13 \text { with ill-defined nodules }\end{array}$ \\
\hline ground glass opacity & $16 / 29[55 \%]$ & $\begin{array}{l}\text { 10/16 with dependent densities in } \\
\text { hypostasis/insufficient ventilation; } \\
1 / 16 \text { with mosaic-pattern in obesity; } \\
1 / 16 \text { with lung contusion after thoracic } \\
\text { trauma; } \\
\text { 4/16 with infectious bronchiolitis }\end{array}$ & $19 / 30[63 \%]$ & $\begin{array}{l}\text { 9/19 with dependent densities in } \\
\text { hypostasis/insufficient ventilation; } \\
\text { 5/19 in pulmonary venous conges- } \\
\text { tion; } \\
4 / 19 \text { ground glass of unknown origin; } \\
1 / 19 \text { with mosaic-pattern in chronic } \\
\text { pulmonary embolism }\end{array}$ \\
\hline fibrosis & $0 / 29[0 \%]$ & & $5 / 30[17 \%]$ & $\begin{array}{l}4 / 5 \text { with discrete septal thickening } \\
\text { and traction bronchiectasis } \\
1 / 5 \text { with UIP-pattern including honey- } \\
\text { combing }\end{array}$ \\
\hline pleural thickening & $14 / 29[48 \%]$ & $\begin{array}{l}10 / 14 \text { due to acute cardio-pulmonary } \\
\text { disease; } \\
4 / 14 \text { with mild uncharacteristic pleural } \\
\text { thickening }\end{array}$ & $16 / 30[53 \%]$ & $\begin{array}{l}\text { 9/16 symmetric apical pleural thick- } \\
\text { ening; } \\
2 / 16 \text { with pleuropneumonia; } \\
2 / 16 \text { with suspected pleural metasta- } \\
\text { ses; } \\
2 / 16 \text { adherent to fibrotic parenchymal } \\
\text { changes; } \\
1 / 16 \text { with tuberculous pleurisy }\end{array}$ \\
\hline pleural effusion & $8 / 29[28 \%]$ & $\begin{array}{l}7 / 8 \text { with pleuropneumonia; } \\
1 / 8 \text { with hematothorax }\end{array}$ & $14 / 30[47 \%]$ & $\begin{array}{l}\text { 6/14 cardiovascular causes; } \\
\text { 4/14 with pleuropneumonia; } \\
\text { 4/14 with lung cancer or pleural me- } \\
\text { tastasis }\end{array}$ \\
\hline consolidation & $10 / 29[33 \%]$ & $\begin{array}{l}\text { 7/10 with bronchopneumonia; } \\
2 / 10 \text { with pneumonia in pulmonary } \\
\text { embolism } \\
1 / 10 \text { poststenotic in lung cancer }\end{array}$ & $8 / 30[27 \%]$ & $\begin{array}{l}4 / 8 \text { with bronchopneumonia; } \\
3 / 7 \text { with pneumonia in pulmonary } \\
\text { embolism; } \\
1 / 8 \text { poststenotic in lung cancer }\end{array}$ \\
\hline $\begin{array}{l}\text { respiratory motion } \\
\text { artifacts }\end{array}$ & $0 / 29[0 \%]$ & & $7 / 30[23 \%]$ & \\
\hline \multicolumn{5}{|c|}{ preliminary radiological diagnoses [category] } \\
\hline „malignancy“ & $3 / 29[10 \%]$ & & $8 / 30[27 \%]$ & \\
\hline "cardiac" & $0 / 29[0 \%]$ & & $6 / 30[20 \%]$ & \\
\hline „pulmonary embolism“ & $2 / 29[7 \%]$ & & $5 / 30[17 \%]$ & \\
\hline „pneumonia“ & $9 / 29[31 \%]$ & & $4 / 30[13 \%]$ & \\
\hline „emphysema“ & $0 / 29[0 \%]$ & & $2 / 30[7 \%]$ & \\
\hline „fibrosis" & $0 / 29[0 \%]$ & & $2 / 30[7 \%]$ & \\
\hline „traumatic“ & $1 / 29[3 \%]$ & & $1 / 30[3 \%]$ & \\
\hline "normal findings" & $13 / 29[45 \%]$ & & $2 / 30[7 \%]$ & \\
\hline „pneumothorax“ & $1 / 29[3 \%]$ & & $0 / 30[0 \%]$ & \\
\hline
\end{tabular}

The following recommendations can be derived from the above statements:

- in the vast majority of cases involving symptomatic elderly patients, gradual escalation of accurate diagnosis can result in a suitable diagnosis of the clinical symptoms.

- Age-specific pulmonary changes include an increase of pulmonary nodules, discrete reticular alterations, isolated lung cysts and a widening of the bronchial diameter. Follow-up using low-dose CT should, in view of the increase in malignant disease as well as idiopathic pulmonary fibrosis in the aging, should be used liberally.

- In practice, however, age-specific changes in symptomatic older patients are overshadowed by other diseases caused by other cardiovascular disorders (cardiac decom- pensation, pulmonary embolism), inflammatory diseases, bronchial pneumonia, pleuropneumonia, bronchiolitis) or malignancies (tumors of the lung, pulmonary and pleural metastasis) as well as emphysematous or characteristic pulmonary disease.

- Particularly with symptomatic patients, an acute CT is frequently characterized by ventilation disorders and hypostasis, and is hardly suitable for the diagnosis of subtle interstitial alterations. A follow-up in a low-symptom position such as in prone position should be tried.

- Classification of pulmonary changes caused by drugrelated influences, systemic disorders and certain past events (e.g. myocardial infarction, previous pneumonia) can be made by correlating with closely-monitored radiological vital signs. 
Prospectively, CT could replace the thoracic X-ray as initial examination by using a low-dose method in combination with iterative reconstruction algorithms. In initial clinical trials, MRI has shown to be of comparable diagnostic value for many issues in the cardiopulmonary region, and has greater value with respect to functional aspects and combined cardiopulmonary indications [38]. In the future, techniques such as MR spectroscopy to differentiate tissue and metabolites, MR elastography to evaluate fibrotic pulmonary changes in-vivo, as well as hybrid technologies such as PET CT and PET MRI can greatly assist radiologists in specialty centers with the classification, dimensioning and monitoring of pulmonary diseases [39-45]. However, it remains unclear to what extent these methods can be validly employed for elderly and very old patients.

There is little empirical data to support what is clinically and radiologically feasible as patients grow older [46]. This especially applies to physiological aging processes and incidental radiological findings in the case of asymptomatic patients beyond 80 years of age.

It remains to be seen whether larger radiological cohort studies will succeed in establishing a chronological correlation of intrinsic and extrinsic events with radiological alterations as a function of age. A lack of sufficient evidence in old age makes the necessity of interdisciplinary-based individual decision-making so much more important.

\section{Affiliations}

Department of Radiology, LungenClinic Grosshansdorf

Department of Pneumology, Airway Research Center North, Member of the German Center for Lung Research (DZL), LungenClinic Grosshansdorf

3 Amalie Sieveking Hospital Academic Teaching Hospital of the University of Hamburg, Diagnostic and Interventional Radiology

${ }^{4}$ University Medical Center Hamburg-Eppendorf, Diagnostic and Interventional Radiology

\section{Literatur}

1 Statistische Ämter des Bundes und der Länder (2010). Demografischer Wandel in Deutschland. Auswirkungen auf Krankenhausbehandlungen und Pflegebedürftige im Bund und in den Ländern. Online aufgerufen über: 2010; Heft 2: https://www.destatis.de/DE/Publikationen/ Thematisch/Bevoelkerung/VorausberechnungBevoelkerung/KrankenhausbehandlungPflegebeduerftige.html (zuletzt 22.7.2014)

2 Statistisches Bundesamt. Statistik der natürlichen Bevölkerungsbewegung. Online aufgerufen über: http://www.gbe-bund.de/gbe10/i? $\mathrm{i}=524: 13791987 \mathrm{D}$ (zuletzt am 22.7.2014)

3 World Health Organization. Definition of an older or elderly person. Online aufgerufen über: http://www.who.int/healthinfo/survey/ ageingdefnolder/en/ (zuletzt am 22.7.2014)

4 Chan ED, Welsh CH. Geriatric respiratory medicine. Chest 1998; 114 : $1704-1733$

5 Dyer $C$. The interaction of ageing and lung disease. Chron Respir Dis 2012; 9: 63-67

6 de Bisschop C, Marty ML, Tessier JF et al. Expiratory flow limitation and obstruction in the elderly. Eur Respir J 2005; 26: 594-601

7 Ontell FK, Moore EH, Shepard JA et al. The costal cartilages in health and disease. Radiographics 1997; 17: 571 - 577

8 Polkey MI, Harris ML, Hughes PD et al. The contractile properties of the elderly human diaphragm. Am J Respir Crit Care Med 1997; 155: $1560-1564$

9 Fukuchi $Y$. The aging lung and chronic obstructive pulmonary disease: similarity and difference. Proc Am Thorac Soc 2009; 6: 570-572

10 Verbeken EK, Cauberghs M, Mertens I et al. The senile lung. Comparison with normal and emphysematous lungs. 1. Structural aspects. Chest 1992: 101: $793-799$
11 Verbeken EK, Cauberghs M, Mertens I et al. The senile lung. Comparison with normal and emphysematous lungs. 2. Functional aspects. Chest 1992; 101: 800-809

12 Pride NB. Aging and changes in lung mechanics. Eur Respir J 2005; 26 : 563-565

13 Janssens JP, Pache JC, Nicod LP. Physiological changes in respiratory function associated with ageing. Eur Respir J 1999; 13: 197-205

14 PA Gevenois, Scillia P, de Maertelaer $V$ et al. The effects of age, sex, lung size, and hyperinflation on CT lung densitometry. Am J Roentgenol 1996; 167: 1169-1173

15 Halbert RJ, Natoli JL, Gano A et al. Global burden of COPD: systematic review and meta-analysis. Eur Respir J 2006; 28: 523-532

16 Teramoto S, Ishii M. Aging, the aging lung, and senile emphysema are different. Am J Respir Crit Care Med 2007; 175: 197-1978; author reply 198

17 de Torres JP, Bastarrika G, Wisnivesky JP et al. Assessing the relationship between lung cancer risk and emphysema detected on low-dose CT of the chest. Chest 2007; 132: 1932-1938

18 Sashidhar K, Gulati M, Gupta D et al. Emphysema in heavy smokers with normal chest radiography: detection and quantification by HCRT. Acta Radiol 2002; 43: 60-65

19 Bankier AA, De Maertelaer V, Keyzer $C$ et al. Pulmonary emphysema: subjective visual grading versus objective quantification with macroscopic morphometry and thin-section CT densitometry. Radiology 1999; 211: $851-858$

20 Topalovic M, Exadaktylos V, Peeters A et al. Computer quantification of airway collapse on forced expiration to predict the presence of emphysema. Respir Res 2013; 14: 131

21 Lee KW, Chung SY, Yang I et al. Correlation of aging and smoking with air trapping at thin-section $\mathrm{CT}$ of the lung in asymptomatic subjects. Radiology 2000; 214: 831 - 836

22 Henschke CI, McCauley DI, Yankelevitz D et al. Early Lung Cancer Action Project: overall design and findings from baseline screening. Lancet 1999; 354: 99-105

23 Swensen SJ, Jett JR, Hartman T et al. Screening for lung cancer with CT: Mayo Clinic experience. Radiology 2003; 226: 756- 761

24 Naidich DP, Bankier AA, MacMahon $\mathrm{H}$ et al. Recommendations for the management of subsolid pulmonary nodules detected at CT: a statement from the Fleischner Society. Radiology 2013; 266: 304-317

25 MacMahon H, Austin JH, Gamsu G et al. Fleischner Society: Guidelines for management of small pulmonary nodules detected on CT scans: a statement from the Fleischner Society. Radiology 2005; 237: 395-400

26 Cottin V, Richeldi $L$. Neglected evidence in idiopathic pulmonary fibrosis and the importance of early diagnosis and treatment. Eur Respir Rev 2014; 23: $106-110$

27 Matsuoka S, Uchiyama K, Shima H et al. Bronchoarterial ratio and bronchial wall thickness on high-resolution CT in asymptomatic subjects: correlation with age and smoking. Am J Roentgenol 2003; 180: 513 518

28 Petersen J, Wille MM, Raket LL et al. Effect of inspiration on airway dimensions measured in maximal inspiration CT images of subjects without airflow limitation. Eur Radiol 2014; 24: 2319-2325

29 Raghu G, Collard HR, Egan JJ et al. ATS/ERS/JRS/ALAT Committee on Idiopathic Pulmonary Fibrosis: An official ATS/ERS/JRS/ALAT statement: idiopathic pulmonary fibrosis: evidence-based guidelines for diagnosis and management. Am J Respir Crit Care Med 2011; 183: $788-824$

30 Cottin V, Cordier JF. Velcro crackles: the key for early diagnosis of idiopathic pulmonary fibrosis? Eur Respir J 2012; 40: 519-521

31 Jin GY, Lynch D, Chawla A et al. Interstitial lung abnormalities in a CT lung cancer screening population: prevalence and progression rate. Radiology 2013; 268: 563-571

32 Sverzellati $N$, Guerci L, Randi $G$ et al. Interstitial lung diseases in a lung cancer screening trial. Eur Respir J 2011; 38: 392 - 400

33 Copley SJ, Wells AU, Hawtin KE et al. Lung morphology in the elderly: comparative CT study of subjects over 75 years old versus those under 55 years old. Radiology 2009; 251: $566-573$

34 Doyle TJ, Hunninghake GM, Rosas IO. Subclinical interstitial lung disease: why you should care. Am J Respir Crit Care Med 2012; 185: $1147-1153$

35 Otake S, Takahashi M, Ishigaki T. Focal pulmonary interstitial opacities adjacent to thoracic spine osteophytes. Am J Roentgenol 2002; 179: $893-896$

36 Slabaugh SL, Maio V, Templin M et al. Prevalence and risk of polypharmacy among the elderly in an outpatient setting: a retrospective co- 
hort study in the Emilia-Romagna region, Italy. Drugs Aging 2010; 27 : $1019-1028$

37 Camus $P$, Fanton A, Bonniaud $P$ et al. Interstitial lung disease induced by drugs and radiation. Respiration 2004; 71: $301-326$

38 Biederer J. Heussel CP, Puderbach $M$ et al. Functional magnetic resonance imaging of the lung. Semin Respir Crit Care Med 2014; 35: $74-82$

39 Thind $K$, Chen A, Friesen-Waldner L et al. Detection of radiation-induced lung injury using hyperpolarized (13) C magnetic resonance spectroscopy and imaging. Magn Reson Med 2012: (Epub)

40 Lee EY, Wong CS, Fung SL et al. SUV as an adjunct in evaluating disease activity in idiopathic pulmonary fibrosis - a pilot study. Nucl Med Commun 2014; 35: 631-637

41 Win T, Thomas BA, Lambrou $T$ et al. Areas of normal pulmonary parenchyma on HRCT exhibit increased FDG PET signal in IPF patients. Eur J Nucl Med Mol Imaging 2014; 41: 337-342
42 Mariappan YK, Glaser KJ, Levin DL et al. Estimation of the absolute shear stiffness of human lung parenchyma using $1 \mathrm{H}$ spin echo, echo planar MR elastography. J Magn Reson Imaging 2013, (Epub)

43 Velde GV, De Langhe E, Poelmans J et al. Magnetic Resonance Imaging for Noninvasive Assessment of Lung Fibrosis Onset and Progression: Cross-Validation and Comparison of Different Magnetic Resonance Imaging Protocols With Micro-Computed Tomography and Histology in the Bleomycin-Induced Mouse Model. Invest Radiol 2014, (Epub)

44 Cleveland ZI, Virgincar RS, Qi Y et al. 3D MRI of impaired hyperpolarized 129 Xe uptake in a rat model of pulmonary fibrosis. NMR Biomed 2014, (Epub)

45 Wielpütz M, Kauczor HU. MRI of the lung: state of the art. Diagn Interv Radiol 2012; 18: $344-353$

46 Hansell DM. Thin-Section CT of the Lungs: The Hinterland of Normal. Radiology 2010; 256: 695-711 